ORIGINAL ARTICLE

\title{
Lung function changes in coke oven workers during 12 years of follow up
}

\author{
J Wu, D Griffiths, I A Kreis, C Darling
}

Occup Environ Med 2004;61:686-691. doi: 10.1136/oem.2003.009381

See end of article for authors' affiliations ....................

Correspondence to: A/Prof. I A Kreis, Graduate School' of Public Health, University of

Wollongong, NSW 2522, Australia; irene_kreis@ uow.edu.au

Accepted 29 January 2004
Aims: To investigate the effect of exposure to coke oven emissions on the lung function of coke oven workers.

Methods: The study population, followed from 1978 and 1990, was 580 male workers with at least two sets of lung function measurements ( $F V C, \mathrm{FEV}_{1}, \mathrm{FEV} / \mathrm{FVC}$, and $\mathrm{FEF}_{25-75 \%}$ ). An annual rate of change (time slope) for age and height adjusted lung function index was estimated for each subject. This "time slope" was then treated as the response variable in a weighted multiple regression analysis with selected predictors.

Results: For all 580 subjects, each year of working in the "operation" group (the most exposed) was found to increase the FVC decline by around $0.7 \mathrm{ml} /$ year $(95 \% \mathrm{Cl} 0.1$ to $1.3 \mathrm{ml} /$ year). After the exclusion of 111 subjects without detailed work history, the above finding was confirmed and each year of exposure in "operation" was also found to increase the $\mathrm{FEV}_{1}$ decline by around $0.8 \mathrm{ml} /$ year $(95 \% \mathrm{Cl} 0.1$ to $1.4 \mathrm{ml}$ / year).

Conclusions: These findings are consistent with the results of previous cross-sectional studies. Work duration in the most exposed position in the coke ovens was associated with increased annual decline for $\mathrm{FVC}$ and $\mathrm{FEV}_{1}$. The estimated effect of one year of work exposure in "operation" is equivalent, in terms of the reduction in lung function, to an estimated 2.1 pack-years of smoking for FVC and 1.2 pack-years of smoking for $\mathrm{FEV}_{1}$.
C oke oven emissions are a mixture of volatile materials produced during destructive distillation of coal and can be expected to affect workers' lung function. ${ }^{12}$ While lung function of coke oven workers has been investigated in several cross-sectional studies, ${ }^{2-5}$ we have found no reported longitudinal studies.

A health surveillance system for coke oven workers started in an Australian steelworks in October 1978 and was modified in July 1990. A study on the period prior to the 1990 modification presented a system overview and a crosssectional analysis of lung function data. ${ }^{6}$ It showed that lower values of FVC and $\mathrm{FEV}_{1}$ were related to work duration. ${ }^{6}$ In the current study, a longitudinal analysis was conducted. Although longitudinal data are often also analysed crosssectionally, ${ }^{7}$ longitudinal analysis is more valuable because it uses information about change over time in individuals. ${ }^{8}$

\section{MATERIALS AND METHODS}

Study population

Analysis was limited to male subjects with at least two sets of lung function measurements between October 1978 and July 1990. A small number $(n=22)$ of females was excluded. A detailed description of the population has been given previously. ${ }^{6}$ The system allowed workers to freely withdraw. Of the 1701 registered male coke oven workers, 580 (around $34 \%$ ) had at least two sets of lung function measurements. This study was approved by the ethics committee of the University of Wollongong, Australia.

Lung function, smoking, and occupational exposure The methods of measuring lung function, estimating smoking level, and assessing coke oven emission exposure in this study are as previously reported. ${ }^{6}$

Lung function indices analysed in this study were forced vital capacity (FVC), forced expiratory volume in one second $\left(\mathrm{FEV}_{1}\right)$, ratio of $\mathrm{FEV}_{1}$ to $\mathrm{FVC}$ expressed as $100 \times \mathrm{FEV}_{1} / \mathrm{FVC}$, and forced mid-expiratory flow $\left(\mathrm{FEF}_{25-75 \%}\right)$. A set of lung function tests was conducted on each subject on recruitment. Each subject was retested at approximately yearly intervals after working at the coke ovens for five or ten years (depending on the job). $\mathrm{FEF}_{25-75 \%}$ was measured only after January 1983.

Subjects were classified as non-smokers, current smokers, or ex-smokers. The cumulative smoking level of current smokers was measured as the standard pack-year unit. There was insufficient information to estimate daily cigarette consumption for ex-smokers for whom smoking duration (years) was used.

Four exposure categories ("operation", "maintenance", "electricity", and "other") were used. It was assumed that subjects in "operation" were most exposed to coke oven emissions, while "maintenance" and "electricity" groups had intermediate exposure, and "other" were least exposed.

The database did not include detailed work history, which was traced from salary records for 469 subjects. Each was then classified into the exposure group for which he had the longest employment duration prior to the last lung function tests. For the other 111 subjects, current job positions, as recorded in the database, were used to assign workers to exposure groups.

The time that each subject spent in each exposure group was also recorded. Work time in "operation" and work time in positions other than "operation" are regarded as more accurately indicating accumulated exposure levels than does work location.

\section{Statistical methods}

Lung function of each subject in the study population was measured repeatedly. Multilevel mixed modelling or a two stage approach, as used in this study, have been recommended for analyses of such correlated data. ${ }^{10-12}$ First, for each subject, the annual rate of change (time slope) for each 


\section{Main messages}

- Work in the "operation" function in coke works during the period of this study (1978-90) is associated with an increased decline in FVC and $\mathrm{FEV}_{1}$.

- The estimated effect of one year of exposure is equivalent in terms of the reduction in lung function to an estimated 2.1 pack-years of smoking for FVC and 1.2 pack-years of smoking for $\mathrm{FEV}_{1}$.

lung function index was estimated using simple linear regression, with time as the sole predictor. Then the "time slope" was treated as the response variable in a multiple regression analysis.

Before "time slope" was estimated, coefficients from reference regressions were used to adjust lung function measurements to those of a man 35 years old and $175 \mathrm{~cm}$ high. Regressions published by Gore et al for healthy Australian adult male lifetime non-smokers were used for this purpose, as detailed earlier. ${ }^{6}{ }^{13}$ Prior adjustment for age and height effects allows the exclusion of age and height from multiple regression analysis, avoiding the correlation of age with other predictors such as exposure duration, and refining the multiple regression analysis.

Weighted least squares regression was used to allow for the varying quality of the "time slope" estimates. ${ }^{14}$ Serial lung function measurements with a longer follow up duration and a larger number of test points produce better "time slope" estimates to which more weight should be given. ${ }^{15}{ }^{16}$ The standard error (SE) of the "time slope" in a linear regression for any lung function index for any subject can be estimated as: estimate of $\operatorname{SE}(\beta)=\sigma / \mathrm{SXX}^{0.5} \cdot{ }^{17}$ In this formula, $\sigma$ is the standard deviation of the noise in a simple linear regression model and $\mathrm{SXX}=\Sigma\left(\mathrm{X}-\mathrm{X}_{\text {mean }}\right)^{2}$ is the corrected sum of squares for the time measurements. All subjects are assumed to have the same standard deviation, $\sigma$, for their regression relationships involving a particular lung function measurement. While not strictly true, this assumption is preferable to estimating the standard deviation separately for each subject. First, such estimates cannot be derived if there are only two measurements. Second, there is substantial unreliability of individual estimates when there are only a few measurements. It is unnecessary to know the value of $\sigma$, since only relative SEs are needed. So, for the weighted least-squares multiple regression analysis, each "time slope" was weighted using the corresponding SXX in the simple linear regression from which that "time slope" was calculated.

The predictors used in the multiple regression models for "time slope" were smoking, duration (years) of working at the coke ovens, and percentage of predicted lung function value at the first test time (compared to the "healthy" population of the reference regressions). ${ }^{13}$ The percentage of predicted value for each lung function index at the first test is included in the multiple regression models because it has been reported to be a strong predictor for the rate of annual lung function change. ${ }^{18-20}$ Variables related to work location were not included because our preliminary analyses showed they had no significant predictive value.

\section{RESULTS}

Table 1 summarises the population characteristics of individuals. Subjects in "operation" were slightly younger on average than those in the other three groups. The groups were of similar average height. Around $85 \%$ of subjects were either current smokers or ex-smokers. For subjects classified in "operation", the average work duration in "operation" was

\section{Policy implications}

- Coke oven emission standards at the time were not sufficient to protect the lung function of coke oven workers.

around 13 years, with on average less than one year in other positions. For the other three groups, broadly the same applied in reverse. Around $30 \%$ of all subjects had a mixed work history.

Table 2 shows the distributions of subjects by different number of tests and by follow up duration. More than $80 \%$ of subjects underwent three or more sets of lung function tests. The average follow up time was around seven years as reported in our previous study. ${ }^{6}$ Around $87 \%$ of subjects had a follow up time of three or more years.

The "time slopes" (after age and height adjustment of the raw lung function data) of lung function vary substantially. The overall average "time slopes" (and their standard deviations) are -26.1 (101.8) ml/year, -20.7 (191.1) ml/ year, -0.05 (3.3) \%/year, and $-1.3 \quad$ (350.9) $\mathrm{ml} / \mathrm{s} \cdot \mathrm{year}$ respectively for $\mathrm{FVC}, \mathrm{FEV}_{1}, \mathrm{FEV}_{1} / \mathrm{FVC}$, and $\mathrm{FEF}_{25-75 \%}$. For subjects in "operation", the average "time slopes" (and their standard deviations) are -23.0 (95.9) $\mathrm{ml} / \mathrm{year},-13.3$ (160.1) $\mathrm{ml} /$ year, 0.04 (3.0) \%/year, and -12.5 (300.5) $\mathrm{ml} / \mathrm{s} \cdot$ year respectively for $\mathrm{FVC}, \mathrm{FEV}_{1}, \mathrm{FEV}_{1} / \mathrm{FVC}$, and $\mathrm{FEF}_{25-75 \%}$. For subjects from the other three groups combined, the average "time slopes" (and their standard deviations) are -31.5 (111.1) ml/year, -33.3 (234.4) ml/year, -0.2 (3.7) \%/year, and 22.0 (438.7) $\mathrm{ml} / \mathrm{s} \cdot$ year respectively for $\mathrm{FVC}, \mathrm{FEV}_{1}, \mathrm{FEV}_{\mathrm{l}} /$ FVC, and $\mathrm{FEF}_{25-75 \%}$.

Multiple regression models were fitted using weighted least squares to the time slopes for $\mathrm{FVC}, \mathrm{FEV}_{1}, \mathrm{FEV}_{1} / \mathrm{FVC}$, and $\mathrm{FEF}_{25-75 \%}$. Table 3 shows the coefficients of predictors for these regressions. Between $5 \%$ and $-16 \%$ of the variation in the annual lung function changes could be explained by the regression models for $\mathrm{FVC}, \mathrm{FEV}_{1}$, and $\mathrm{FEV}_{1} / \mathrm{FVC}$ in table 3, while for $\mathrm{FEF}_{25-75 \%}$, only around $1.5 \%$ of the variation could be explained. The number of observations for $\mathrm{FEF}_{25-75 \%}$ is smaller, as this measure was not introduced until 1983.

The average percentages of predicted values for FVC and $\mathrm{FEV}_{1}$ at the first test time were around 85\% (table 1). After controlling for smoking and the percentage of predicted value at the first test time, we found that years of working in "operation" increased the annual FVC decline by around $0.7 \mathrm{ml}(\mathrm{p}=0.02,95 \%$ confidence interval (CI) 0.1 to $1.3 \mathrm{ml} /$ year). Similarly, each year of working in positions other than "operation" increased the annual FVC decline by around $0.6 \mathrm{ml}(\mathrm{p}=0.03,95 \% \mathrm{CI} 0.1$ to $1.1 \mathrm{ml} / \mathrm{year})$. Although the relation between each year of working in "operation" and the annual decline in $\mathrm{FEV}_{1}$ was (marginally) not statistically significant (the associated excess annual decline was around $0.5 \mathrm{ml}, \mathrm{p}=0.09,95 \% \mathrm{CI}-0.1$ to $1.0 \mathrm{ml} /$ year), no duration effects for occupational exposure were observed on the annual declines for $\mathrm{FEV}_{1} / \mathrm{FVC}$ and $\mathrm{FEF}_{25-75 \%}$.

Smoking effects on annual lung function change were observed. For ex-smokers, each year of smoking was associated with an excess annual decline in $\mathrm{FEV}_{1}$ of around $0.5 \mathrm{ml}$ ( $\mathrm{p}=0.003,95 \%$ CI 0.2 to $0.9 \mathrm{ml} / \mathrm{year})$, and in $\mathrm{FEV}_{\mathrm{l}} /$ FVC of around $0.01 \%(\mathrm{p}=0.0004,95 \%$ CI 0.005 to 0.02 $\% /$ year). Each pack-year for current smokers was associated with an excess annual decline in FVC of around $0.5 \mathrm{ml}$ ( $\mathrm{p}=0.0006,95 \%$ CI 0.2 to $0.8 \mathrm{ml} / \mathrm{year}$ ), in $\mathrm{FEV}_{1}$ of around $0.6 \mathrm{ml}(\mathrm{p}=0.0001,95 \% \mathrm{CI} 0.3$ to $0.9 \mathrm{ml} / \mathrm{year})$, and in $\mathrm{FEV}_{\mathrm{l}} /$ FVC of around $0.009 \%(\mathrm{p}=0.0003,95 \%$ CI 0.004 to 0.01 $\% /$ year). 
Table 1 Characteristics of subjects in the coke oven lung function surveillance system with at least two sets of lung function tests

\begin{tabular}{|c|c|c|c|c|c|}
\hline & \multicolumn{4}{|l|}{ Group } & \multirow[b]{2}{*}{ Total } \\
\hline & Operation & Maintenance & Electricity & Other & \\
\hline Subjects (no.) & 365 & 103 & 59 & 53 & 580 \\
\hline Age at first test (years), mean (SD) & $36.8(11.2)$ & $41.3(12.0)$ & $40.4(11.6)$ & $41.9(12.5)$ & $38.4(11.7)$ \\
\hline Min-max (years) & $17.7-64.0$ & $18.0-62.5$ & $20.4-61.0$ & $20.4-63.5$ & $17.7-64.0$ \\
\hline Age at last test (years), mean (SD) & $44.5(11.3)$ & 48.4 (11.7) & $48.1(10.6)$ & $46.6(11.4)$ & $45.8(11.4)$ \\
\hline Min-max (years) & $19.7-65.0$ & $25.2-65.5$ & $29.0-64.4$ & $26.4-64.5$ & $19.7-65.5$ \\
\hline Height $(\mathrm{cm})$, mean (SD) & $170.6(7.1)$ & $170.0(5.6)$ & $171.3(7.4)$ & $173.4(7.4)$ & $170.8(7.0)$ \\
\hline Min-max $(\mathrm{cm})$ & $152-191$ & $154-185$ & $154-191$ & $161-194$ & $152-194$ \\
\hline Non-smokers, no. $(\%)^{*}$ & $57(15.6)$ & $19(18.5)$ & $6(10.2)$ & $6(11.3)$ & $88(15.2)$ \\
\hline Ex-smokers, no. $(\%)^{*}$ & $104(28.5)$ & $32(31.0)$ & $24(40.7)$ & $14(26.4)$ & $174(30.0)$ \\
\hline Smoking duration, mean (SD) & $15.7(10.7)$ & $20.4(13.3)$ & $17.7(10.9)$ & $15.1(11.2)$ & $16.8(11.4)$ \\
\hline Current smokers, no. (\%)* & $204(55.9)$ & $52(50.5)$ & $29(49.1)$ & $33(62.3)$ & $318(54.8)$ \\
\hline Pack-years, mean (SD) & $14.9(16.2)$ & $18.5(21.5)$ & $23.1(27.6)$ & $17.2(29.3)$ & $16.5(20.0)$ \\
\hline Duration in "operation" (years)t, mean (SD) & $13.1(7.5)$ & $0.9(2.3)$ & $0.2(1.2)$ & $0.9(1.7)$ & $8.5(8.5)$ \\
\hline Duration other than in "operation" (years)t, mean (SD) & $0.6(1.9)$ & $16.0(8.3)$ & $16.9(6.7)$ & $14.5(8.5)$ & $6.3(9.0)$ \\
\hline Pure history $\ddagger$, no. (\%) & $290(79.5)$ & $52(50.5)$ & $36(61.0)$ & $29(54.7)$ & $407(70.2)$ \\
\hline Mixed history§, no. (\%) & $75(20.5)$ & $51(49.5)$ & $23(39.0)$ & $24(45.3)$ & $173(29.8)$ \\
\hline \multicolumn{6}{|l|}{$\%$ of predicted value at first test time , mean (SD) } \\
\hline FVC & $85.6(12.9)$ & $86.0(10.5)$ & $87.2(10.6)$ & $87.1(11.9)$ & $86.0(12.2)$ \\
\hline $\mathrm{FEV}_{1}$ & 84.5 (15.5) & $85.1(13.4)$ & $85.6(13.7)$ & $83.9(14.8)$ & $84.7(14.9)$ \\
\hline $\mathrm{FEV}_{1} / \mathrm{FVC}$ & $97.8(10.6)$ & $98.4(9.0)$ & $97.1(8.9)$ & $95.8(10.1)$ & $97.7(10.1)$ \\
\hline $\mathrm{FEF}_{25-75 \%}$ & $81.6(26.1)$ & $82.3(35.6)$ & $83.2(29.4)$ & $90.4(30.6)$ & $82.3(28.5)$ \\
\hline
\end{tabular}

$\mathrm{SD}$, standard deviation.

*Number and proportions of non-smokers, ex-smokers, and current-smokers in each group.

†Duration up to the last lung function tests.

¥Pure history: subjects had only one type of work position during the surveillance period.

§Mixed history: subjects had more than one type of work position during the surveillance period.

TThe numbers of subjects in calculation for FEV $1, F V C$, and FEV $1 / F V C$ are 580 ; for $\mathrm{FEF}_{25-75 \%} 419$.

There were 111 subjects with no detailed work history from salary records in this data set. New multiple regression analyses were conducted after excluding these 111 subjects. The results are shown in table 4 and strengthen, but do not change, the qualitative nature of our conclusions. The coefficients of work duration in "operation" were observed to have bigger magnitudes and smaller $\mathrm{p}$ values compared with those in table 3. Each year of working in "operation" increased the annual decline of FVC around $1.0 \mathrm{ml} / \mathrm{year}$ ( $p=0.004,95 \%$ CI 0.3 to $1.7 \mathrm{ml} /$ year $)$. Each year of working in "operation" was also now found to be significantly associated with an excess annual decline in $\mathrm{FEV}_{1}$ of around $0.8 \mathrm{ml} /$ year ( $\mathrm{p}=0.03,95 \% \mathrm{CI} 0.1$ to $1.4 \mathrm{ml} /$ year) .

Our regression analyses in table 3 and table 4 showed that the initial percentage of predicted lung function value at the first test time is a significant predictor for future lung function change. Regressions were fitted again after excluding initial percentage of predicted value from the predictors. Observed associations were all qualitatively unchanged.

To analyse the separate duration effects associated with the exposure to the three types of positions "maintenance", "electricity", and "other", the models for FVC and FEV 1 in table 4 were refitted. It was found that the coefficient for "work duration in "electricity" was marginally significant $(\beta=-0.84, p=0.047)$ for FVC; the coefficients for "work duration in "maintenance" and "work duration in 'other" were not significant for FVC. The coefficients for these three predictors were not significant for $\mathrm{FEV}_{1}$. The coefficients for other predictors were similar to those reported in table 4 .

\section{DISCUSSION}

There are no prior studies of longitudinal changes in the lung function of coke oven workers. This study provides valuable data on effects of exposure to coke oven emissions. Our data can be compared with results of cross-sectional studies, and with those of longitudinal studies in other environments.

To provide readily interpretable yardsticks on exposure effects, some extrapolations were made using results in table 4 . These regressions predict the annual rate of change (time slope) of lung function as a function of given predictors. A constant time slope was assumed for each subject in the data analyses although it is quite likely that in

\begin{tabular}{|c|c|c|c|c|c|}
\hline & \multicolumn{4}{|l|}{ Group } & \multirow[b]{2}{*}{ Total } \\
\hline & Operation & Maintenance & Electricity & Other & \\
\hline \multicolumn{6}{|c|}{ Number of lung function tests } \\
\hline $2-3$ & $74(20.3 \%)$ & 31 (30.1\%) & $10(17.0 \%)$ & $25(47.2 \%)$ & 140 \\
\hline $4-5$ & $80(21.9 \%)$ & $23(22.3 \%)$ & $13(22.0 \%)$ & $15(28.3 \%)$ & 131 \\
\hline $6-10$ & 129 (35.3\%) & $30(29.1 \%)$ & $30(50.8 \%)$ & $12(22.6 \%)$ & 201 \\
\hline $11-12$ & $82(22.5 \%)$ & $19(18.5 \%)$ & $6(10.2 \%)$ & $1(1.9 \%)$ & 108 \\
\hline \multicolumn{6}{|c|}{ Follow up duration (years) } \\
\hline $0-$ & $37(10.1 \%)$ & $11(10.6 \%)$ & $7(11.9 \%)$ & $23(43.4 \%)$ & 78 \\
\hline $3-$ & $50(13.7 \%)$ & 20 (19.4\%) & $7(11.9 \%)$ & $12(22.6 \%)$ & 89 \\
\hline $5-$ & $147(40.3 \%)$ & $36(35.0 \%)$ & $28(47.4 \%)$ & $14(26.4 \%)$ & 225 \\
\hline$\geqslant 10$ & $131(35.9 \%)$ & $36(35.0 \%)$ & $17(28.8 \%)$ & $4(7.6 \%)$ & 188 \\
\hline Total & 365 & 103 & 59 & 53 & 580 \\
\hline
\end{tabular}



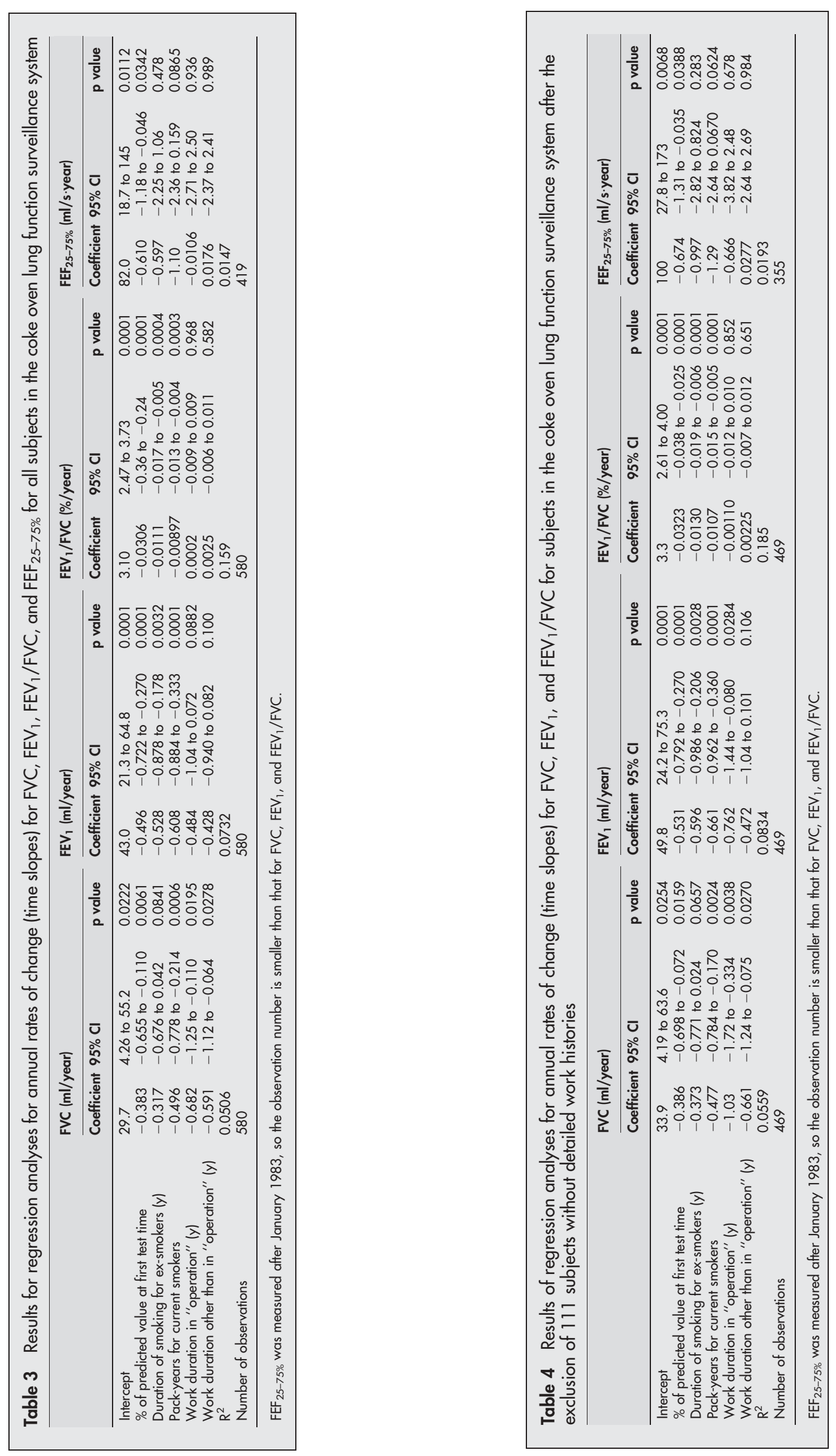

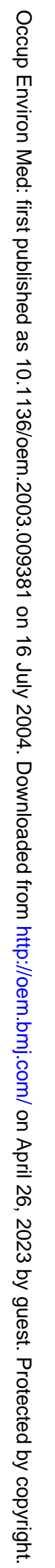


some subjects the slope will change over time. In this case the slope represents average slope. For a fixed period of time, the estimated extra lung function reduction for a typical subject with occupational exposure, compared with a typical subject without exposure, is the product of the coefficient of exposure (work duration in "operation") and the square of the length of time. The estimated total lung function losses in FVC and $\mathrm{FEV}_{1}$ attributable to 10 years of exposure in "operation" are around $103 \mathrm{ml}$ and $76 \mathrm{ml}$ respectively. These estimates are broadly similar to those from our previous cross-sectional study with estimated total losses in FVC and $\mathrm{FEV}_{1}$ attributable to 10 years of exposure in "operation" of around $187 \mathrm{ml}$ and $83 \mathrm{ml} .{ }^{6}$

Compared with a typical non-smoker, it is estimated that the extra FVC and $\mathrm{FEV}_{1}$ losses for a typical current smoker with 10 pack-years of smoking during 10 years are around $48 \mathrm{ml}$ and $66 \mathrm{ml}$ respectively. In our cross-sectional study, 10 pack-years of current smoking led to (estimated) $45 \mathrm{ml}$ and $118 \mathrm{ml}$ reductions in FVC and $\mathrm{FEV}_{1}$ respectively. ${ }^{6}$ If the total lung function reduction due to occupational exposure is averaged for the 10 years, the effect, in reducing lung function, of one year of work exposure in "operation" is equivalent to an estimated 2.1 pack-years of smoking for FVC and 1.2 pack-years of smoking for $\mathrm{FEV}_{1}$. Coke oven emissions and smoking might be associated with different pathological changes of the respiratory system, since the latter was found to have adverse impact on $\mathrm{FEV}_{1} / \mathrm{FVC}$. As discussed previously, ${ }^{6}$ smoking usually causes a lung function pattern typical of obstructive lung disease, while the pattern of effects from exposure to coke oven emissions seems to suggest restrictive lung disease. ${ }^{14}$

Neither an occupational exposure effect nor a smoking effect was found in $\mathrm{FEF}_{25-75 \%}$ in this study. The within subject coefficient of variation (CV) for $\mathrm{FEF}_{25-75 \%}$ is around $6 \%$ while the CV for FVC is only around 3\%. ${ }^{9}$ This may explain the small values of $\mathrm{R}^{2}$ for the fitted regressions for $\mathrm{FEF}_{25-75 \%}$.

Because of the limited literature on lung function of coke oven workers, we have extended our comparisons to other longitudinal studies. The lung function of 1677 coal miners was followed for 16 years; ${ }^{19}$ the estimated annual $\mathrm{FEV}_{1}$ loss caused by coal dust at an average exposure level was around $3.6 \mathrm{ml}$. In a study of the lung function of 236 underground coal miners followed for an average of 11 years, each year of exposure was reported to increase $\mathrm{FEV}_{1}$ slope by around 0.7 $\mathrm{ml} /$ year $(\mathrm{p}=0.03) .{ }^{21}$ In the same study, each pack-year of smoking was found to be associated with an excess annual $\mathrm{FEV}_{1}$ decline of around $0.7 \mathrm{ml} /$ year $(\mathrm{p}=0.006)$. These results are similar to our findings.

Most subjects began their jobs in the coke ovens long before the lung function surveillance system started. ${ }^{6}$ Therefore, the percentage of predicted value at the first test time in table 1 reflected the lung function when subjects were recruited into the surveillance system. When the initial percentage of predicted value was used to predict the following annual lung function decline in a similarly designed study, it was reported that the coefficients were around $-1.61 \mathrm{ml} /$ year, $-0.973 \mathrm{ml} /$ year, and $-0.0676 \% /$ year for $\mathrm{FVC}, \mathrm{FEV}_{1}$, and $\mathrm{FEV}_{1} / \mathrm{FVC}$ respectively. ${ }^{18}$ These findings were broadly similar to ours.

Coke oven emissions contain complex compounds. Monitoring coke oven emissions is usually based upon the benzene soluble fraction (BSF) of total particulate material. ${ }^{6}$ Many individual compounds might have adverse effects on the lung function, although the extreme complexity of the mix makes these effects unclear. ${ }^{1}$

Our study has some limitations. Exposure assessment was based on time working at the coke ovens in various positions, not on individual monitoring data. This cannot fully reflect actual individual exposure levels. The only detailed exposure information available is the average exposure for people in "operation" during the years 1983-85: $0.19 \mathrm{mg} / \mathrm{m}^{3}$ benzene soluble fraction. ${ }^{6}$ When quantitative monitoring data are not available, employment duration in specific job categories is a better surrogate measure of exposure than the crude job status alone. ${ }^{42}$

Another aspect that has not been taken into account is the time of the exposure. Exposure in the early years was different to and possibly worse than in the later part. There is no simple effective way of addressing this issue.

Other limitations include the relatively small sample size and large variation in the data. The study sample only represents $34 \%$ of the subjects in the surveillance system. ${ }^{6}$ Comparison between the subjects in this study and those without longitudinal lung function data indicated that these two groups had similar lung function (at the first tests) and similar occupational exposure. However, subjects in this study were older (on average) with fewer current smokers. ${ }^{6}$ The $\mathrm{R}^{2}$ values in our regression models range from around $1.5 \%$ to $15 \%$. For regressions relating annual lung function loss to suspected factors in similarly designed longitudinal studies, $\mathrm{R}^{2}$ values are typically below $7 \%{ }^{18}{ }^{19}{ }^{23}$ However, it should be noted that age and height were excluded from our multiple regression analyses. Accordingly, $\mathrm{R}^{2}$ should be substantially smaller than for regressions that include age and height as predictors. There is still a large proportion of variation unexplained in the regression models. This might be caused by technical variation (for example, measurement and effort), and by biological variation (for example, temporary illness and circadian rhythms). ${ }^{14} 19$ It is generally not possible to control (or reduce) these variations in longitudinal studies, because of the long follow up time and the large number of repeated measurements conducted on each individual.

In conclusion, the findings from longitudinal analysis of the lung function of coke oven workers were consistent with those from our previous cross-sectional study. Work duration in "operation" contributed to excess annual declines in FVC and $\mathrm{FEV}_{1}$. Further investigation is still recommended because of limitations such as the lack of individual monitoring data and the relatively small population in this study.

\section{ACKNOWLEDGEMENTS}

The authors thank Mrs Helen Calvert and her colleagues for substantial help, and the University of Wollongong for financial support.

\section{Authors' affiliations \\ J Wu, I A Kreis, Graduate School of Public Health, University of Wollongong, Australia \\ D Griffiths, School of Mathematics \& Applied Statistics, University of Wollongong, Australia \\ C Darling, BlueScope Steel, Port Kembla, Australia}

\section{REFERENCES}

1 Smith WM. Evaluation of coke oven emissions. J Occup Med 1971;13:69-74.

2 Walker DD, Archibald RM, Atffield MD. Bronchitis in men employed in the coke industry. Br J Ind Med 1971;28:358-63.

3 Madison R, Afifi AA, Mittman C. Respiratory impairment in coke oven workers: relationship to work exposure and bronchial inflammation detected by sputum cytology. J Chron Dis 1984;37:167-76.

4 Chau N, Bertrand JP, Guenzi $M$, et al. Lung function in retired coke oven plant workers. Br J Ind Med 1992;49:316-25.

5 Corhay JL, Bury T, Louis R, et al. Bronchial responsiveness in active steelworkers. Eur Respir J 1998;1 1:272-7.

6 Wu J, Kreis IA, Griffiths D, et al. Cross-sectional study on lung function of coke oven workers: a lung function surveillance system from 1978 to 1990. Occup Environ Med 2002;59:816-23.

7 Bande J, Clement J, Van De Woestijne KP. The influence of smoking habits and body weight on vital capacity and $\mathrm{FEV}_{1}$ in male air force personnel: a longitudinal and cross-sectional analysis. Am Rev Respir Dis 1980;122:781-90. 
8 Vollmer WM, Johnson LR, McCamant LE, et al. Longitudinal versus crosssectional estimation of lung function decline-further insights. Stat Med 1988;7:685-96

9 Hankinson JL. Pulmonary function testing in the screening of workers: guidelines for instrumentation, performance, and interpretation. J Occup Med 1986;28:1081-92.

10 Matthews JNS, Altman DG, Campbell MJ, et al. Analysis of serial measurements in medical research. BMJ 1990;300:230-5.

11 Burton P, Gurrin L, Sly P. Extending the simple linear regression model to account for correlated responses: an introduction to generalized estimating equations and multi-level mixed modelling. Stat Med 1998;17:1261-91.

12 Schwartz DA, Donham KJ, Olenchock SA, et al. Determinants of longitudinal changes in spirometric function among swine confinement operators and farmers. Am J Respir Crit Care Med 1995;151:47-53.

13 Gore CJ, Crockett AJ, Pederson DG, et al. Spirometric standards for healthy adult lifetime nonsmokers in Australia. Eur Respir J 1995;8:773-82.

14 American Thoracic Society. Lung function testing: selection of reference values and interpretative strategies. Am Rev Respir Dis 1991;144:1202-18.

15 Burrows B, Lebowitz MD, Camilli AE, et al. Longitudinal changes in forced expiratory volume in one second in adults. Methodologic considerations and findings in healthy nonsmokers. Am Rev Respir Dis 1986;133:974-80.
16 Hoek G, Brunekreef B. Time trends in repeated spirometry in children. Eur Respir J 1992;5:553-9.

17 Weisberg S. Applied linear regression, 2nd edn. New York: Wiley 1985:4-27.

18 O'Connor GT, Sparrow D, Weiss ST. A prospective longitudinal study of methacholine airway responsiveness as a predictor of pulmonary-function decline: the Normative Aging Study. Am J Respir Crit Care Med 1995; 152:87-92.

19 Love RG, Miller BG. Longitudinal study of lung function in coal-miners. Thorax 1982;37:193-7.

20 Rijcken B, Weiss ST. Longitudinal analyses of airway responsiveness and pulmonary function decline. Am J Respir Crit Care Med 1996;154:s246-9.

21 Wang ML, Petsonk EL, Beeckman LA, et al. Clinically important FEV 1 declines among coal miners: an exploration of previously unrecognised determinants. Occup Environ Med 1999;56:837-44.

22 Soutar CA, Hurley JF. Relation between dust exposure and lung function in miners and ex-miners. Br J Ind Med 1986:43:307-20.

23 Berry G, McKerrow CB, Molyneux MKB, et al. A study of the acute and chronic changes in ventilatory capacity of workers in Lancashire cotton mills. $\mathrm{Br} J$ Ind Med 1973;30:25-36.

\section{$\mathrm{ECHO}$}

\section{Experts urge curb on pollutants to protect future generations}

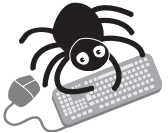

Please visit the Occupational and

Environmental Medicine website [www. occenvmed. com] for a link to the full text of this article.
Experts in Britain say that government and industry must act to reduce release of - chemicals into the environment to limit potential risks to human health, especially - health of the fetus in later life. Precautions are needed, they say-from safety testing to taxing marketed chemicals of environmental concern, as mooted by the Royal Commission on Environmental Pollution-even though supporting evidence is limited. Public distrust of environmental chemicals has grown since the pesticide scares of the last century, against a backdrop of increasing incidences of breast cancer and abnormal testicular development, though epidemiological research has not confirmed that organochlorine compounds are to blame. Far more abundant and potentially dangerous are phthalates, which recent animal studies have linked with abnormalities of testicular development in offspring and for which postnatal effects on reproductive function in humans have been suggested.

Existing evidence of damage to aquatic organisms by environmental chemicals is especially relevant because of the parallel with the fluid environment of the human fetus, and maternal exposure to organochlorine compounds has been shown to reduce fertility and increase testicular cancer in the fetus. "As fetal life is increasingly recognised as a time when susceptibility to adult disease may be induced as a result of dietary or lifestyle effects of the mother, more effects of chemical exposures seem likely to emerge."

Nailing the environmental culprits is tough because of problems with methodology and confounding factors - that is why the experts are urging precautionary action.

\ Sharpe RM, et al. British Medical Journal 2004;328:447-451. 